\title{
Influence of serological factors and BMI on the blood pressure/hematocrit association in healthy young men and women
}

This article was published in the following Dove Press journal:

Vascular Health and Risk Management

6 May 2014

Number of times this article has been viewed

\author{
Beatriz Y Salazar Vázquez ${ }^{1,2,5}$ \\ Miguel A Salazar Vázquez ${ }^{2,3}$ \\ Adolfo Chávez-Negrete ${ }^{4}$ \\ Galileo Escobedo ${ }^{2}$ \\ Pedro Cabrales ${ }^{5}$ \\ Shankar Subramaniam ${ }^{5}$ \\ Marcos Intaglietta ${ }^{5}$ \\ Ruy Pérez-Tamayo ${ }^{2}$ \\ 'Faculty of Medicine, Universidad \\ Juárez del Estado de Durango, \\ Victoria de Durango, Dgo, Mexico; \\ ${ }^{2}$ Department of Experimental \\ Medicine, Faculty of Medicine, \\ Universidad Nacional Autónoma de \\ México, Hospital General de México \\ Dr Eduardo Liceaga, México City, \\ Mexico; ${ }^{3}$ Department of Pediatrics, \\ Hospital General de Zona No. I, \\ Instituto Mexicano del Seguro Social, \\ Durango, Dgo, Mexico; ${ }^{4}$ Hospital de \\ Especialidades, Instituto Mexicano \\ de Seguro Social, México DF, Mexico; \\ ${ }^{5}$ Department of Bioengineering, \\ University of California, San Diego, \\ CA, USA
}

Correspondence: Beatriz Y Salazar Vázquez

Department of Bioengineering, University of California, San Diego, 9500 Gilman Drive, La Jolla, CA 92093-04I2, USA Tel +l 8585344275

Email bsalazarvazquez@gmail.com

\begin{abstract}
The association between mean arterial blood pressure (MAP) and hematocrit (Hct) as a surrogate for blood viscosity was investigated in a young (average $20.0 \pm 2.3$ years), healthy population of 174 men and 442 women. Health status was assessed by clinical examination and serological evaluation. Individuals with severe anemia or hemoconcentration, prior traumas or major surgical intervention, smokers, and pregnant or lactating women were excluded from the study. The MAP/Hct association was positive and significant $(P=0.04)$ for women and negative, albeit not significantly so, for men. The MAP/Hct association was also evaluated in subgroups of the same population with a progressive step-by-step exclusion of: individuals with cholesterol $>200 \mathrm{mg} / \mathrm{dL}$; triglycerides $>200 \mathrm{mg} / \mathrm{dL}$; body mass index $>25 \mathrm{~kg} / \mathrm{m}^{2}$; and glucose $>100 \mathrm{mg} / \mathrm{dL}$. This consecutively reduced the strength of the positive MAP/Hct association in women, which became negative - although not significantly so - when all anomalously high factors were excluded. The same trend was found in men. Our study indicates that previously reported positive trends in the relationship between the MAP and Hct in the population are not present in a young, healthy population of men or women that excludes individuals with the confounding factors of above normal serological values and BMI.
\end{abstract}

Keywords: blood pressure, blood viscosity, hematocrit, vascular resistance, endothelial dysfunction

\section{Introduction}

A direct relationship between hypertension, elevated hematocrit (Hct), and blood viscosity was found in studies pioneered by Letcher et al. ${ }^{1}$ These results were confirmed by findings of the Edinburgh Artery Study, a study that evaluated the blood pressure/ viscosity association in 1,592 men and women aged 55-74 years. ${ }^{2}$ This study concluded that there was evidence of a strong association between blood viscosity and arterial pressure, independently of confounding factors. The same conclusion was reached by the Gubbio Population Study (2,809 men and women aged 25-74 years). ${ }^{3}$ That study reported a significant independent association between Hct and the prevalence of hypertension and a positive relationship between Hct and blood pressure.

Studies conducted in a population ${ }^{4}$ of $>100,000$ blood donors in the Netherlands reported a positive association between hemoglobin levels and systolic and diastolic blood pressure in adult men and women ( $49.3 \pm 12.5$ and $42.4 \pm 13.7$ years). This study included individuals considered to be healthy with data adjusted for age, body mass index (BMI), mean daily temperature, season, smoking, and antihypertensive drug treatment.

However, studies in populations that can be clinically evaluated tend to show that a significant positive association between MAP and Hct is related to age and/or clinical 
conditions that may coexist with endothelial dysfunction. ${ }^{5-7}$ Conversely, healthy controls in these studies tend not to show a positive correlation between MAP and Hct.

Normal endothelial function regulates peripheral vascular resistance due to changes in blood viscosity, by producing the vasodilators nitric oxide and prostacyclin via mechanotransduction in response to flow-induced shear stress on the vascular wall. ${ }^{8}$ Shear stress at the vessel wall due to blood viscosity, flow, and blood vessel diameter therefore contributes to the autoregulation of blood pressure if the endothelium is responsive and - presumably - healthy. ${ }^{9}$

In a previous study, we investigated the relationship between MAP and Hct in a healthy population residing in the same locality ${ }^{10}$ however, factors that may influence the MAP/ Hct trend were not explored. In the present study, we investigated the relationship of MAP versus Hct in a relatively uniform population of younger adults whose health status was determined by clinical interview and anthropometric and serological measurements, with the aim of finding readily measurable variables that affect the MAP/Hct trend.

\section{Methods}

The study was carried out in an open population of young adults aged 17-25 years in the city of Durango, Mexico, invited to participate by means of radio and newspaper announcements made by the Universidad Juárez del Estado de Durango. The study was approved by the Ethical Committee of the Universidad Nacional Autónoma de México, México DF, Mexico. Written informed consent was obtained and signed by all participants prior to the investigation. Parents or guardians provided the written consent for minors (individuals under 18 years).

Both females and males who were considered healthy blood donors as determined by the analysis of a written questionnaire, blood pressure measurement not showing hypertension, and the absence of the exclusion criteria, were all included in the study. Individuals were excluded from the study with diagnosis of hemorheological perturbations, such as: severe anemia (blood hemoglobin $<10$ and $12 \mathrm{~g} / \mathrm{dL}$ for women and men respectively); hemoconcentration (hemoglobin $>18$ and $20 \mathrm{~g} / \mathrm{dL}$ for women and men respectively); traumas or major surgical intervention in the preceding six months; and smoking habits (those who in the previous 6 months consumed at least one cigarette). We additionally excluded subjects with previous or recent diagnosis of diabetes mellitus, cardiovascular diseases, chronic hepatic or renal disease, inflammatory or autoimmune disorders, acute or chronic infectious diseases, cancer, endocrine disorders, as well as pregnant or lactating women.
All participants were asked to provide their clinical history. Height, weight, BMI, and blood pressure (criteria of the VII Joint National Committee on Prevention, Detection, and Treatment; High Blood Pressure, National Heart, Lung, and Blood Institute; 2003) were measured at this time.

Hematocrit varies through the day as a function of fluid and food intake, level of exercise, etc. Therefore, to ensure a degree of uniformity of hydration, participants were summoned at 8 am for blood sampling, after 8-12 hours of fasting. Blood pressure was measured first after 5 minutes of resting in the sitting position with an automatic instrument (Omron model BP742, Omron Healthcare, Inc., Bannockburn, IL, USA) three times in the left arm at heart level, at 5-minute intervals and averaged. Glucose, cholesterol, and triglycerides were measured in drawn blood samples with the instrument Accutrend ${ }^{\circledR}$ GCT (Roche Diagnostics GmbH, Mannheim, Germany), which uses a drop of blood obtained from an index finger puncture. Hematocrit and hemoglobin determinations were made by the same method using the instrument HemoCue Hb 201 (HemoCue, Inc., Cypress, CA, USA). These tests were subsequently repeated for individuals who had significant clinical alterations, using standard laboratory analysis techniques.

\section{Statistical analysis}

The association between MAP and Hct for the population was evaluated by determining the Spearman's correlation coefficient of these two variables. The influence of serological factors and BMI upon the MAP/Hct relationship was assessed by the consecutive step-by-step removal of individuals who had values above the normal thresholds for these parameters and reanalyzing the level of association by means of the Spearman's correlation coefficient, excluding individuals according to the backward-stepwise selection method. ${ }^{11}$

The order of removal was established by ranking the serological parameters and the BMI above the normal threshold that caused the steepest slope on the MAP/Hct association (ie, produced the strongest effect) when only the individuals with this parameter anomaly were investigated. Individuals with the parameter showing the strongest effect were removed first. Statistical analysis was performed using the GraphPad Prism 5 software (GraphPad Software, Inc., La Jolla, CA, USA). Differences were considered significant when $P<0.05$.

\section{Results}

The study included 616 individuals (442 women and 174 men), aged $17-25$ years. The average age was $20.0 \pm 2.3$ years. The principal characteristics of the population studied are given in Table 1. 
Table I Demographic, anthropometric, and serologic characteristics of the young adult population examined in the municipality of the city of Durango, Mexico

\begin{tabular}{|c|c|c|}
\hline Sex & Men $=174$ & Women $=442$ \\
\hline Age, years & $20.4 \pm 2.5$ & $19.7 \pm 2.2$ \\
\hline Weight, kg & $75.8 \pm 15.3$ & $60.1 \pm 11.8$ \\
\hline Height, m & $1.74 \pm 0.07$ & $1.60 \pm 0.06$ \\
\hline $\mathrm{BMI}, \mathrm{kg} / \mathrm{m}^{2}$ & $24.8 \pm 4.3$ & $23.4 \pm 4.1$ \\
\hline Mean arterial pressure, $\mathrm{mmHg}$ & $91.2 \pm 7.4$ & $85.0 \pm 8.3$ \\
\hline Cardiac frequency, beats/minute & $67.2 \pm 11.5$ & $71.0 \pm 11.7$ \\
\hline Waist-to-hip ratio & $0.94 \pm 0.06$ & $0.89 \pm 0.06$ \\
\hline Body fat, \% & $\begin{array}{l}22.9 \pm 6.5 \\
\text { nr } 18 \%-24 \%\end{array}$ & $\begin{array}{l}28.1 \pm 8.3 \\
\text { nr } 20 \%-28 \%\end{array}$ \\
\hline Hematocrit, \% & $48.2 \pm 3.2$ & $43.1 \pm 2.8$ \\
\hline $\begin{array}{l}\text { Cholesterol, mg/dL } \\
\mathrm{nr} 150-200 \mathrm{mg} / \mathrm{dL}\end{array}$ & $163.7 \pm 17.4$ & $162.7 \pm 16.8^{*}$ \\
\hline $\begin{array}{l}\text { Glucose, } \mathrm{mg} / \mathrm{dL} \\
\mathrm{nr} 70-100 \mathrm{mg} / \mathrm{dL}\end{array}$ & $97.4 \pm 18.5$ & $95.4 \pm 15.1 *$ \\
\hline $\begin{array}{l}\text { Triglycerides, } \mathrm{mg} / \mathrm{dL} \\
\mathrm{nr}<150 \mathrm{mg} / \mathrm{dL}\end{array}$ & $150.7 \pm 98.0$ & $142.9 \pm 85.0^{*}$ \\
\hline
\end{tabular}

Notes: All demographic and anthropometric parameters, including Hct, are significantly different $(P<0.002)$. Serological parameters $\left(^{*}\right)$ are not significantly different.

Abbreviations: BMI; body mass index; nr, normal range; Hct, hematocrit.

The relationship between MAP and Hct was evaluated for the whole study population separated by sex. Results are presented in Figure 1 showing that the trend of MAP/Hct association is positive and significant for women $(P=0.04$; $r=0.10)$, and negative - albeit not significant - for men $(P=0.91 ; r=-0.05)$.

As shown in Table 1, men and women presented variability in parameter values. Some individuals exceeded the normal serological and BMI thresholds. The differences between and men and women in BMI, MAP, glucose, cholesterol, and triglycerides are typical of the Mexican population; these same trends have been previously reported. ${ }^{12}$ The difference in Hct between men and women is found in all healthy young populations. ${ }^{13}$

The slope of the MAP/Hct association was evaluated for groups whose individuals had each of their serological and BMI values above the normalcy threshold. This analysis showed that the steepest slope for the MAP/Hct relationship occurred in individuals with cholesterol levels $>200 \mathrm{mg} / \mathrm{dL}$; progressively lesser effects were observed in the order of parameters shown in Table 2.

This information was used to reevaluate the MAP/Hct relationship in groups in which individuals with values above the threshold for a given parameter were progressively removed from the respective group, in the order shown in Table 2, obtaining the results shown in Tables 3 and 4 .

The net effect of this treatment of the data was the nonsignificant lowering of the value of $m$ (slope) (Tables 3 and 4) in the association between MAP and Hct. Excluding women with abnormally high cholesterol caused their positive MAP/ Hct association to become not statistically significant, changing the $P$-value from $0.04-0.14$. The subsequent exclusion of women with high triglycerides yielded $P=0.90$ for the MAP/ Hct association. Further step-by-step removal of individuals with above threshold values of BMI and glucose caused the trend to become negative (but not significant). Applying the procedure to the data from men caused the negative slope of
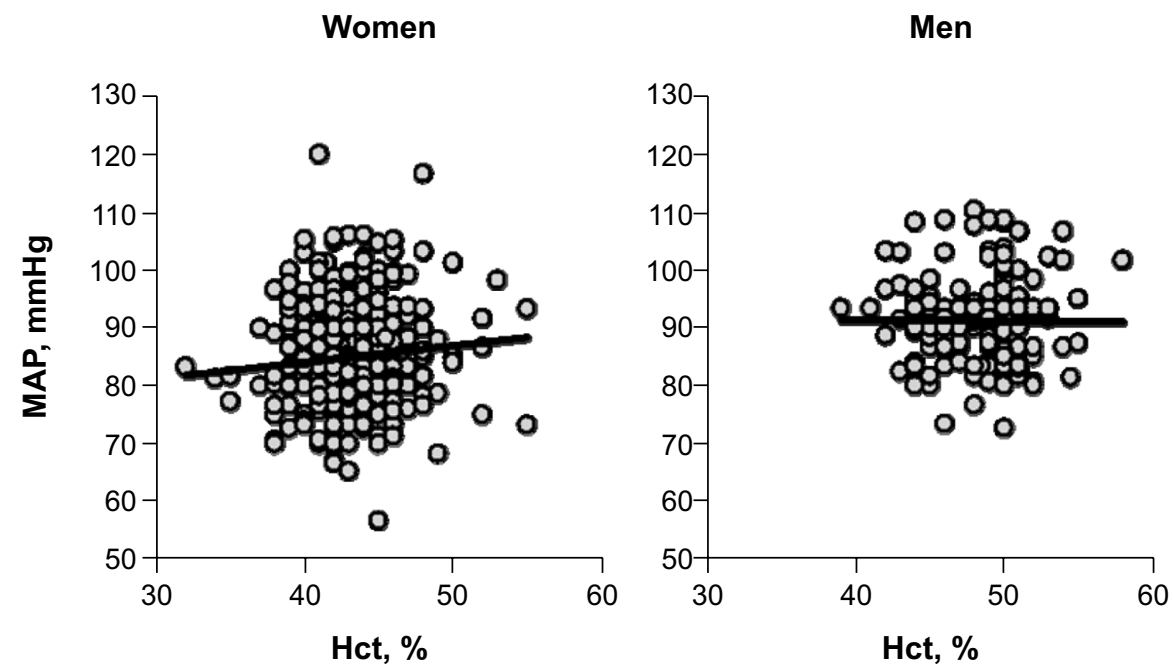

Figure I MAP plotted as function of Hct for the study population of individuals described in Table I.

Notes: The association MAP/Hct is positive and significant $(P=0.04, r=0.10)$ for women $(n=442)$ and negative but not significant $(r=-0.05)$ for men $(n=174)$. This association becomes negative but not significant for women when individuals with serological and BMI values exceeding normal values are excluded. The same exclusion applied to men causes the association to become more negative without reaching significance.

Abbreviations: MAP, mean arterial blood pressure; Hct, hematocrit; BMI, body mass index; n, number. 
Table 2 Thresholds defining the upper limit of parameters for the normal population

\begin{tabular}{llc}
\hline Thresholds & \multicolumn{2}{l}{ Average and STD of \% exceeding threshold } \\
\cline { 2 - 3 } & Men & Women \\
\hline $\begin{array}{r}\text { Cholesterol } \\
200 \mathrm{mg} / \mathrm{dL}\end{array}$ & $223.4 \pm 22.8 ; 4.0 \%$ & $219.3 \pm 20.4 ; 4.1 \%$ \\
$\begin{array}{c}\text { Triglycerides } \\
200 \mathrm{mg} / \mathrm{dL}\end{array}$ & $300.2 \pm 109.5 ; 21.3 \%$ & $297.9 \pm 108.6 ; 15.4 \%$ \\
$\begin{array}{c}\mathrm{BMI} \\
25 \mathrm{~kg} / \mathrm{m}^{2}\end{array}$ & $27.9 \pm 3.2 ; 46.6 \%$ & $28.5 \pm 3.5 ; 28.7 \%$ \\
$\begin{array}{c}\text { Glucose } \\
100 \mathrm{mg} / \mathrm{dL}\end{array}$ & $113.7 \pm 15.0 ; 39.1 \%$ & $110.0 \pm 10.0 ; 36.0 \%$ \\
\hline
\end{tabular}

Abbreviations: STD, standard deviation; BMI, body mass index.

the MAP/Hct association to become progressively steeper, ie, with a numerically greater negative slope $\mathrm{m}$, although without reaching significance.

\section{Discussion}

The principal result of this study is that - in a young healthy population, with normal serological parameters and BMI - the relationship between MAP and Hct for men and women shows a nonsignificant negative trend. This result is different from that found in several studies of older populations showing positive and significant trends. ${ }^{2,3}$ We also show that excluding healthy women who present serological parameters beyond the threshold of normalcy reduces the strength (ie, the slope and the significance) of the association between MAP and Hct, which becomes negative although not significant when the confounding factors are removed.

In the case of men, the MAP/Hct association is negative but not significant for the whole population; removing individuals with anomalous parameter values reduces the slope and the strength of the association. However, this reduction is not significant.

Table 3 Women

\begin{tabular}{lllll}
\hline & $\mathbf{n}$ & $\mathbf{m}, \mathbf{m m H g} / \mathbf{H c t}$ & $\boldsymbol{P}$ & $\mathbf{r}$ \\
\hline All women & 442 & $0.285 \pm 0.140$ & 0.04 & 0.10 \\
All minus chol $>200 \mathrm{mg} / \mathrm{dL}$ & 424 & $0.214 \pm 0.145$ & $\mathrm{~ns}$ & 0.07 \\
All minus chol, trig $>200 \mathrm{mg} / \mathrm{dL}$ & 363 & $0.020 \pm 0.156$ & $\mathrm{~ns}$ & 0.00 \\
All minus chol, trig, & 266 & $-0.022 \pm 0.178$ & $\mathrm{~ns}$ & 0.00 \\
BMI $>25 \mathrm{~kg} / \mathrm{m}^{2}$ & & & & \\
All minus chol, trig, BMl, & 166 & $-0.032 \pm 0.213$ & $\mathrm{~ns}$ & -0.01 \\
glu $>100 \mathrm{mg} / \mathrm{dL}$ & & & & \\
\hline
\end{tabular}

Notes: Statistical characteristics of the association MAP versus Hct as a function of threshold of chol, trig, BMI, and glu.

Abbreviations: MAP, mean arterial blood pressure; m, slope; Hct, hematocrit; chol, cholesterol; trig, triglycerides; BMI, body mass index; glu, glucose; ns, nonsignificant association; $n$, number.
Table 4 Men

\begin{tabular}{lllll}
\hline & $\mathbf{n}$ & $\mathbf{m}$ (slope) & $\mathbf{P}$ & $\mathbf{r}$ \\
\hline All men & 174 & $-0.020 \pm 0.179$ & $\mathrm{~ns}$ & -0.05 \\
All minus chol $>200 \mathrm{mg} / \mathrm{dL}$ & 167 & $-0.024 \pm 0.185$ & $\mathrm{~ns}$ & -0.0 I \\
All minus chol, trig $>200 \mathrm{mg} / \mathrm{dL}$ & 134 & $-0.035 \pm 0.206$ & $\mathrm{~ns}$ & -0.02 \\
$\begin{array}{l}\text { All minus chol, trig, } \\
\text { BMI }>25 \mathrm{~kg} / \mathrm{m}^{2}\end{array}$ & 77 & $-0.019 \pm 0.260$ & $\mathrm{~ns}$ & -0.00 \\
$\begin{array}{l}\text { All minus chol, trig, BMI, } \\
\text { glu }>100 \mathrm{mg} / \mathrm{dL}\end{array}$ & 39 & $-0.193 \pm 0.368$ & $\mathrm{~ns}$ & -0.09 \\
\hline $\begin{array}{l}\text { Notes: Statistical characteristics of the association MAP versus } \\
\text { threshold of chol, trig, BMl, and glu. }\end{array}$ & \\
$\begin{array}{l}\text { Abbreviations: m, slope; Hct, hematocrit; chol, cholesterol; trig, triglycerides; } \\
\text { BMl, body mass index; glu, glucose; ns, nonsignificant association; n, number. }\end{array}$
\end{tabular}

The path taken to investigate the effect of above threshold serological parameters and $\mathrm{BMI}$ on the MAP/Hct association is somewhat arbitrary since it does not account for the incidence of occurrence (ie, proportion of individuals) of the abnormalities in the population. The significant result is that there is no MAP/Hct association in a population that has normal serological data and BMI, and that - in the tested population - only $9 \%$ of women and $22 \%$ of men could be considered normal, according to the chosen criteria.

The proportion of males with no BMI or serology abnormalities was $28.7 \%$ versus $38.7 \%$ for women, a difference due to the incidence of overweight and obesity in men (46.6\% versus $28.5 \%$ ).

Blood viscosity is primarily determined by Hct, being a nonlinear function of this parameter. ${ }^{13,14}$ However, the relationship between blood viscosity and Hct for the normal range of variability of Hct in the population can be considered linear, ${ }^{10}$ which facilitates the study of the MAP/ blood viscosity relationship in large populations, where the measurement of blood viscosity could be substituted with the measurement of Hct.

In our study, we used Hct as a surrogate for blood viscosity, an assumption that may not be accurate in older individuals who may show altered plasma composition, particularly concerning fibrinogen and other rheological abnormalities, such as decreased red blood cell flexibility. ${ }^{15}$ Although we did not evaluate blood fibrinogen, this assumption should be accurate for the population studied, given its age and health. ${ }^{16}$

Blood viscosity is one of the determinants of peripheral vascular resistance ${ }^{17}$ and, hence, in a circulatory system consisting of rigid tubes increasing blood viscosity increases vascular resistance, according to the Hagen-Poiseuille law. Supporting experimental data on the effect of blood viscosity on MAP originate with the classical studies of Richardson and Guyton ${ }^{18}$ and those of Messmer et al. ${ }^{19}$ However, the Hct 
changes studied were significantly greater than those associated with the variability of Hct in the normal population.

Experimental studies on changes of Hct in the range of variability of the normal population yield different results. Martini et $\mathrm{al}^{20,21}$ showed in awake animals that acutely increasing blood viscosity above normal by about $10 \%$ through altering isovolemic hemoconcentration significantly lowered the MAP and increased the cardiac output. It should be noted that these are acute responses that may not extrapolate to chronic conditions. However, these changes of blood pressure lasting several hours do not appear to be regulated by baroreceptor responses.

The control of peripheral vascular resistance in the normal organism independently from the activity of the central nervous system is linked to mechanotransduction, via shear stress at the blood vessel wall that governs the production of vasodilators. ${ }^{22,23}$ Shear stress is in part determined by blood viscosity, ${ }^{24,25}$ which can have two opposing effects on peripheral vascular resistance. Namely, it can have a direct effect due to simple hemodynamic hindrance and a second, opposite effect due to the response to vasodilator release.

\section{Evidence for lack of association between MAP and blood viscosity}

Our results support the concept that increased Hct does not lead to an increased MAP in the young, healthy population. Furthermore, our present and previous studies indicate that the association may be negative, with increased Hct leading to lower MAP. Therefore, it is of interest to briefly analyze the results of previous studies in terms of the characteristics of the populations tested.

The relationship between blood viscosity and MAP was studied in a healthy population of 84 men and 65 women (30.6 \pm 8.0 years) from the city of Durango. The trend of association with MAP/viscosity was negative but not significant for women; there was a negative linear correlation $(r=0.22$; $P=0.03$ ) for men. ${ }^{10}$

The study of de Simone et $\mathrm{a}^{26}$ showed that systolic blood pressure and blood viscosity were negatively correlated in the Native Americans who participated in the Strong Heart Study $(P<0.01) .{ }^{26}$ Conversely, Paul et al ${ }^{27}$ showed that hypertension and anemia, and therefore decreased blood viscosity, were positively correlated. A group of 646 young male office workers (age range, 18-41 years; 28.3 \pm 5.6 ) in Tokyo, Japan, was investigated using multiple regression analysis of systolic (SBP) and diastolic blood pressure (DBP) using Hct, age, BMI, and drinking and smoking habits as independent variables. The results showed that Hct was a significant independent variable for $\mathrm{DBP}(P<0.001)$ but not for $\mathrm{SBP}^{28}$ This association can be interpreted to be representative of a normal endothelial autoregulation of peripheral vascular resistance. ${ }^{29}$

A study of healthy subjects selected from participants in a campaign of prevention of cardiovascular disease $(n=103)$ in Catanzaro, Italy, showed that the only variables that were significantly positively associated were SBP and age, and DBP and Hct. ${ }^{30}$

The effect of aging on endothelial function is evident in women that pass from pre- to postmenopause. ${ }^{31}$ Salazar Vázquez et $\mathrm{al}^{32}$ analyzed the distribution of MAP and Hct in a population of pre- and postmenopause women from the city of Durango, Mexico. In this study, healthy nonsmoking premenopausal women $(n=85)$ showed a nonsignificant negative correlation $(P=0.5)$ between MAP and Hct, while menopausal women $(n=92)$ presented a positive correlation $(P<0.01)$. Women aged $>60$ years in the city of Stockholm, Sweden, $(n=2,189)$ showed an identical MAP/Hct trend to that of menopausal women in Durango. ${ }^{32}$

The study of de Simone et $\mathrm{al}^{33}$ found a significant independent relation between SBP, DBP, MAP, and blood viscosity (measured over a range of shear rates) as well as Hct $(r=0.17-0.23$; all $P<0.05)$ in a cohort of normotensive members of the employed population in New York City. ${ }^{34}$ The study included apparently normal men and women who were 27-75 years old.

Adaptation to altitude increases Hct and $\mathrm{MAP}^{35}$, the increase in MAP preceding the increase in Hct; however, the prolonged residence at high altitude lowers MAP relative to that of sea level residents. ${ }^{36-38}$ The decrease of MAP with altitude is attributed to the relaxation of the vascular smooth muscle, increased collateral circulation, increased vascularization, ${ }^{39}$ higher red blood cell and hemoglobin levels, hypocaloric stress, and respiratory ailments. ${ }^{40,41}$

However, the hypothesis that this may be due to increased mechanotransduction caused by increased Hct and blood viscosity appears to have not been considered. In general, children and young adults of populations that adapt to altitude by increasing Hct have comparatively lower MAP than similarly aged populations at sea level.

A common trend in these studies is that the MAP/Hct association is positive in conditions where the organism has some form of dysfunction; it is not significant in healthy persons.

\section{Conclusion}

Our results show that, in normal healthy males and females, MAP is not elevated when Hct is higher than the norm if 
the serological parameters and the BMI do not exceed the normalcy thresholds. Most studies in the literature that report a positive and significant association between MAP and Hct include older individuals. Values of plasma glucose, cholesterol, and triglycerides exceeding the normal threshold are related to increased blood pressure. Hence, it is not surprising that the exclusion of these individuals lowers the strength of the MAP/Hct association. A mechanism that may in part explain the lack of MAP/Hct association for normal individuals is the increase of shear stress at the blood vessel wall interface due to increased viscosity, which - according to the mechanisms of endothelial biochemical mechanotransduction - increases the release of vasodilators by the endothelium, an effect not present with endothelial dysfunction. ${ }^{8}$

Our results indicate that the increase in Hct in healthy young individuals is not related to the increase of MAP.

\section{Acknowledgment}

This work was supported by a grant FOMIX (Fondo mixto: combined funding) CONACYT (Consejo Nacional de Ciencia y Technología: National Counsel for Science and Technology) clave 66638, México; BY Salazar Vázquez, principal investigator.

\section{Disclosure}

The authors report no conflicts of interest in this work.

\section{References}

1. Letcher RL, Chien S, Pickering TG, Sealey JE, Laragh JH. Direct relationship between blood pressure and blood viscosity in normal and hypertensive subjects. Role of fibrinogen and concentration. Am J Med. 1981;70(6):1195-1202.

2. Fowkes FG, Lowe GD, Rumley A, Lennie SE, Smith FB, Donnan PT. The relationship between blood viscosity and blood pressure in a random sample of the population aged 55 to 74 years. Eur Heart J. 1993;14(5): 597-601.

3. Cirillo M, Laurenzi M, Trevisan M, Stamler J. Hematocrit, blood pressure, and hypertension. The Gubbio Population Study. Hypertension. 1992;20(3):319-326.

4. Atsma F, Veldhuizen I, de Kort W, van Kraaij M, Pasker-de Jong P, Deinum J. Hemoglobin level is positively associated with blood pressure in a large cohort of healthy individuals. Hypertension. 2012;60(4): 936-941.

5. Romero-Corral A, Sert-Kuniyoshi FH, Sierra-Johnson J, et al. Modest visceral fat gain causes endothelial dysfunction in healthy humans. J Am Coll Cardiol. 2010;56(8):662-666.

6. Kregel $\mathrm{KC}$, Zhang HJ. An integrated view of oxidative stress in aging: basic mechanisms, functional effects, and pathological considerations. Am J Physiol Regul Integr Comp Physiol. 2007;292(1):R18-R36.

7. Arcaro G, Cretti A, Balzano S, et al. Insulin causes endothelial dysfunction in humans: sites and mechanisms. Circulation. 2002;105(5): 576-582.

8. Martini J, Cabrales P, Tsai AG, Intaglietta M. Mechanotransduction and the homeostatic significance of maintaining blood viscosity in hypotension, hypertension and haemorrhage. J Intern Med. 2006;259(4): 364-372.
9. Sriram K, Salazar Vázquez BY, Tsai AG, Cabrales P, Intaglietta M, Tartakovsky DM. Autoregulation and mechanotransduction control the arteriolar response to small changes in hematocrit. Am J Physiol Heart Circ Physiol. 2012;303(9):H1096-H1106.

10. Vázquez BY. Blood pressure and blood viscosity are not correlated in normal healthy subjects. Vasc Health Risk Manag. 2012;8:1-6.

11. Motulsky H. Multiple regression. In: Intuitive Biostatistics, A Nonmathematical Guide to Statistical Thinking. 3rd ed. New York, NY: Oxford University Press; 2013:341-356.

12. Stern MP, Rosenthal M, Haffner SM, Hazuda HP, Franco LJ. Sex difference in the effects of sociocultural status on diabetes and cardiovascular risk factors in Mexican Americans. The San Antonio Heart Study. Am J Epidemiology. 1984;120(6):834-851.

13. Kameneva MV, Watach MJ, Borovetz HS. Gender difference in rheologic properties of blood and risk of cardiovascular diseases. Clin Hemorheol Microcirc. 1999;21(3-4):357-363.

14. Pirofsky B. The determination of blood viscosity in man by a method based on Poiseuille's law. J Clin Invest. 1953;32(4):292-298.

15. Baskurt OK, Meiselman HJ. Blood rheology and hemodynamics. Semin Thromb Hemost. 2003;29(5):435-450.

16. Drenos F, Miller GJ, Humphries SE. Increase of plasma fibrinogen levels and variability with age in a sample of middle aged healthy men. Ann Hum Genet. 2007;71(Pt 1):43-53.

17. Baskurt OK, Yalcin O, Meiselman HJ. Hemorheology and vascular control mechanisms. Clin Hemorheol Microcirc. 2004;30(3-4): $169-178$.

18. Richardson TQ, Guyton AC. Effects of polycythemia and anemia on cardiac output and other circulatory factors. Am J Physiol. 1959;197: $1167-1170$.

19. Messmer K, Sunder-Plassmann L, Klövekorn WP, Holper K. Circulatory significance of hemodilution: rheological changes and limitations. Advances in Microcirculation. Editor: Harders H.(Hamburg). S. KargerAG, Basel, Switzerland. 1972;1-77.

20. Martini J, Carpentier B, Negrete AC, Frangos JA, Intaglietta M. Paradoxical hypotension following increased hematocrit and blood viscosity. Am J Physiol Heart Circ Physiol. 2005;289(5): H2136-H2143.

21. Martini J, Tsai AG, Cabrales P, Johnson PC, Intaglietta M. Increased cardiac output and microvascular blood flow during mild hemoconcentration in hamster window model. Am J Physiol Heart Circ Physiol. 2006;291(1):H310-H317.

22. Frangos JA, Eskin SG, McIntire LV, Ives CL. Flow effects on prostacyclin production in cultured human endothelial cells. Science. 1985;227(4693):1477-1479.

23. Yalcin O, Ulker P, Yavuzer U, Meiselman HJ, Baskurt OK. Nitric oxide generation by endothelial cells exposed to shear stress in glass tubes perfused with red blood cell suspensions: role of aggregation. Am J Physiol Heart Circ Physiol. 2008;294(5):H2098-H2105.

24. Melkumyants AM, Balashov SA, Khayutin VM. Endothelium dependent control of arterial diameter by blood viscosity. Cardiovasc Res. 1989;23(9):741-747.

25. Smiesko V, Lang DJ, Johnson PC. Dilator response of rat mesenteric arcading arterioles to increased blood flow. Am J Physiol. 1989; 257(6 Pt 2):H1958-H1965.

26. de Simone G, Devereux RB, Chinali M, Best LG, Lee ET, Welty TK; Strong Heart Study Investigators. Association of blood pressure with blood viscosity in american indians. The Strong Heart Study. Hypertension. 2005;45(4):625-630.

27. Paul B, Wilfred NC, Woodman R, Depasquale C. Prevalence and correlates of anaemia in essential hypertension. Clin Exp Pharmacol Physiol. 2008;35(12):1461-1464.

28. Nishikido N, Kobayashi T, Kashiwazaki H. Hematocrit correlates with blood pressure in young male office workers. Ind Health. 1999;37(1):76-81.

29. Brett SE, Ritter JM, Chowienczyk PJ. Diastolic blood pressure changes during exercise positively correlate with serum cholesterol and insulin resistance. Circulation. 2000;101(6):611-615. 
30. Irace C, Carallo C, Scavelli F, Loprete A, Merante V, Gnasso A. Lack of association between systolic blood pressure and blood viscosity in normotensive healthy subjects. Clin Hemorheol Microcirc. 2012; 51(1):35-41.

31. Maturana MA, Irigoyen MC, Spritzer PM. Menopause, estrogens, and endothelial dysfunction: current concepts. Clinics (Sao Paulo). 2007;62(1):77-86.

32. Vázquez BY, Vázquez MA, Intaglietta M, de Faire U, Fagrell B, Cabrales P. Hematocrit and mean arterial blood pressure in pre- and postmenopause women. Vasc Health Risk Manag. 2009;5(2):483-488.

33. de Simone G, Devereux RB, Chien S, Alderman MH, Atlas SA, Laragh JH. Relation of blood viscosity to demographic and physiologic variables and to cardiovascular risk factors in apparently normal adults. Circulation. 1990;81(1):107-117.

34. Hammond IW, Devereux RB, Alderman MH, Laragh JH. Relation of blood pressure and body build to left ventricular mass in normotensive and hypertensive employed adults. J Am Coll Cardiol. 1988;12(4): 996-1004

35. Zubieta-Calleja GR, Paulev PE, Zubieta-Calleja L, Zubieta-Castillo G. Altitude adaptation through hematocrit changes. J Physiol Pharmacol. 2007;58 Suppl 5(Pt 2):811-818.
36. Cahill E, Rowan SC, Sands M, et al. The pathophysiological basis of chronic hypoxic pulmonary hypertension in the mouse: vasoconstrictor and structural mechanisms contribute equally. Exp Physiol. 2012; 97(6):796-806.

37. Hanna JM. Climate, altitude, and blood pressure. Hum Biol. 1999; 71(4):553-582.

38. Tripathy V, Gupta R. Blood pressure variation among Tibetans at different altitudes. Ann Hum Biol. 2007;34(4):470-483.

39. León-Velarde F, Sanchez J, Bigard AX, Brunet A, Lesty C, Monge C. High altitude tissue adaptation in Andean coots: capillarity, fibre area, fibre type and enzymatic activities of skeletal muscle. J Comp Physiol B. 1993;163(1):52-58.

40. Wolfel EE, Selland MA, Mazzeo RS, Reeves JT. Systemic hypertension at 4,300 $\mathrm{m}$ is related to sympathoadrenal activity. J Appl Physiol (1985). 1994;76(4):1643-1650.

41. Ruiz L, Peñaloza D. Altitude and hypertension. Mayo Clin Proc. $1977 ; 52(7): 442-445$.
Vascular Health and Risk Management

\section{Publish your work in this journal}

Vascular Health and Risk Management is an international, peerreviewed journal of therapeutics and risk management, focusing on concise rapid reporting of clinical studies on the processes involved in the maintenance of vascular health; the monitoring, prevention and treatment of vascular disease and its sequelae; and the involvement of

\section{Dovepress}

metabolic disorders, particularly diabetes. This journal is indexed on PubMed Central and MedLine. The manuscript management system is completely online and includes a very quick and fair peer-review system, which is all easy to use. Visit http://www.dovepress.com/ testimonials.php to read real quotes from published authors. 